\title{
Toxicidade e repelência de extratos de plantas da caatinga sobre Tetranychus bastosi Tutler, Baker \& Sales (Acari: Tetranychidae) em pinhão-manso
}

\author{
XAVIER, M.V.A. ${ }^{*}$; MATOS, C.H.C.1; OLIVEIRA, C.R.F.'; SÁ, M.G.R.'; SAMPAIO, G.R.M.1 \\ ${ }^{1}$ Unidade Acadêmica de Serra Talhada, Universidade Federal Rural de Pernambuco, Fazenda Saco, Margem \\ Direita da BR 232, Sertão do Alto Pajeú, CEP 063 - 56903-970. Serra Talhada, Pernambuco - Brasil. *Autor \\ para correspondencia: vivian_x3@hotmail.com
}

\begin{abstract}
RESUMO: O objetivo deste trabalho foi avaliar o efeito repelente e a toxicidade dos extratos aquosos de Myracrodruon urundeuva Fr. All (Anacardiaceae), Croton blanchetianus Baill (Euphorbiaceae) e Ziziphus joazeiro Mart. (Rhamnaceae,) sobre o ácaro Tetranychus bastosi Tutler, Baker \& Sales associado à cultura do pinhão- manso Jatropha curcas L. Para cada extrato as concentrações utilizadas foram $0,5 \%, 10 \%, 15 \%, 20 \%$ e $25 \%$. Avaliou-se, em teste sem chance de escolha, a mortalidade de fêmeas adultas de T. bastosi submetidas às diferentes concentrações de cada extrato. O delineamento estatístico foi o inteiramente casualizado, com seis tratamentos (testemunha e concentrações dos extratos) e 10 repetições. Os dados foram submetidos à análise de regressão. Também foi avaliado o efeito repelente dos referidos extratos sobre $T$. bastosi, nas concentrações supracitadas. Foi calculado o índice de repelência, percentual de repelência, classificação e índice de segurança. Os dados de percentual de repelência de adultos no tratamento e testemunha foram analisados pelo teste T de Student a $5 \%$ de probabilidade. De uma forma geral os extratos demonstraram efeito tóxico para adultos de $T$. bastosi nas concentrações testadas. O extrato de Z. joazeiro apresentou as maiores taxas de mortalidade $(90 \%)$ média dos indivíduos. No que se refere à repelência destes extratos, todos os tratamentos se mostraram repelentes para fêmeas de $T$. bastosi, classificados como tratamentos repelentes, exceto para a dosagem de $5 \%$ do extrato de $M$. unrundeuva.
\end{abstract}

Palavras-chave: ácaro vermelho, extrato de planta, manejo integrado de pragas, Jatropha curcas.

\begin{abstract}
Toxicity and repellency of caatinga plant extracts on the Tetranychus bastosi Tutler, Baker \& Sales in physic nut. The aim of this study was to evaluate the repellent effect and toxicity of aqueous extracts of $M$. urundeuva All Br. (Anacardiaceae), Croton blanchetianus Baill( Euphorbiaceae ) and Ziziphus joazeiro Mart. (Rhamnaceae) on the mite Tetranychus bastosi Tutler, Baker \& Sales associated with Jatropha curcas. For each extract, the concentrations used were $0,5 \%, 10 \%, 15 \%, 20 \%$ and $25 \%$. It was evaluated, at a nochoice test, the mortality of adult females of $T$. bastosi submitted to different concentrations of each extract. The experimental design was completely randomized with six treatments (control and concentrations of the extracts) and 10 repetitions. The data were subjected to regression analysis. The repellent effect of the extracts over the $T$. bastosi, in the concentrations already mentioned was also evaluated. The repellency index, percentage repellency, classification and safety index were assessed. The data of percentage repellency of adults in treatment and control were analyzed by the $T$ test Student a $5 \%$ probability. In general, the extracts showed toxic effect on adults of $T$. bastosi for the concentrations tested. The extract of $Z$. joazeiro indicated $d$ the highest average mortality rates $(90 \%)$ of individuals. Regarding the repellency of these extracts, all treatments have proved to be repellants for the females of $T$. bastosi classified as repellent treatment, except for the $5 \%$ dose of the extract of $M$. unrundeuva.
\end{abstract}

Keywords: red mite, plant extract, integrated pest management, Jatropha curcas. 


\section{INTRODUÇÃO}

O pinhão-manso Jatropha curcas L. (Euphorbiaceae) é uma planta arbustiva encontrada em quase todas as regiões intertropicais, mas com ocorrência em maior escala nas regiões tropicais e temperadas (Vanzoline et al., 2010; Verona, 2010; Lima et al., 2011; Wang et al., 2011). Desenvolvese bem tanto nas regiões tropicais secas, como nas zonas equatoriais úmidas, e em solos áridos e pedregosos, suportando longos períodos de secas (Heller, 1996).

Segundo Alves et al. (2008) o pinhão-manso apresenta valor medicinal e ornamental e ainda pode ser utilizado como cerca viva. Atualmente, vem sendo considerada uma das mais promissoras oleaginosas do Sudeste, Centro-oeste e Nordeste do Brasil e, segundo alguns autores, pode futuramente chegar a substituir o diesel de fontes não-renováveis (Arruda et al., 2004). Produzir biodiesel a partir do pinhão-manso apresenta algumas vantagens, pois os frutos apresentam crescimento rápido e as sementes possuem alto teor de óleo. Além disso, sua produção tem início nos primeiros anos após o plantio, entre dois e três anos, podendo permanecer por 40 anos, e as plantas podem se desenvolver e produzir em solos de baixa fertilidade (Wang et al., 2011; Visser et al., 2011).

O ácaro Tetranychus bastosi Tutler, Baker e Sales, registrado há alguns anos em Sergipe, e recentemente no Tocantins e em Pernambuco também vem se tornando uma grande ameaça para a produção econômica desta cultura (Pedro-Neto et al., 2013; Barros, 2013).

Os ácaros tetraniquídeos podem ocasionar perdas de até $80 \%$ da produção, devido ao seu potencial reprodutivo, o que tem levado os produtores a utilizarem cada vez maiores quantidades de produtos sintéticos, o que ocasiona severos problemas de resistência de pragas, altos níveis de resíduos em frutos, intoxicação do ambiente e do homem e destruição de inimigos naturais (Soto et al., 2011).

Substâncias provenientes dos produtos do metabolismo secundário das plantas, encontradas nas raízes, folhas, frutos e sementes podem interferir severamente no metabolismo de outros organismos, causando impactos variáveis sobre seus aspectos bioecológicos (Lancher, 2000).

Assim, o objetivo deste trabalho foi avaliar o efeito repelente e a toxicidade dos extratos de aroeira-do-sertão (Myracrodruon urundeuva Fr. All), marmeleiro (Croton blanchetianus Baill) e juazeiro (Ziziphus joazeiro Mart.) sobre o ácaro-praga $T$. bastosi em pinhão-manso.

\section{MATERIAL E MÉTODOS}

Os experimentos foram realizados no Laboratório de Entomologia da Universidade Federal Rural de Pernambuco, Unidade Acadêmica de Serra Talhada (UFRPE/UAST).

\section{Criação dos ácaros}

Ácaros provenientes de plantas de pinhãomanso foram criados em laboratório, segundo metodologia de Matos (2006) e consistiu de placas do tipo gerbox ${ }^{\circledR}$ contendo arenas de folhas de pinhão- manso, as quais foram colocadas com a face adaxial voltada para baixo sobre uma camada de espuma (4 $\mathrm{cm}$ de espessura), umedecida constantemente com água destilada. A água, além de manter a turgescência da folha, serviu de barreira à fuga dos ácaros. Algodão hidrófilo foi utilizado para recobrir toda a borda das folhas, evitando assim a fuga dos ácaros para a face da folha. A cada cinco dias as folhas foram substituídas por outras em melhor estado e os ácaros transferidos com o auxílio de pincel ou pela colocação da antiga folha sobre a arena nova, permitindo assim que os mesmos passem para a nova folha. As criações foram mantidas em câmaras climáticas do tipo B.O.D. (25 $\pm 2^{\circ} \mathrm{C}, 70 \pm 10 \%$ UR e 12 horas de fotofase).

\section{Seleção das espécies vegetais}

A escolha das espécies vegetais utilizadas para obtenção dos extratos baseou-se no referencial disponível na literatura quanto às suas propriedades medicinais. Foram selecionadas três espécies da caatinga pernambucana: a aroeira-do-sertão Myracrodruon urundeuva (Anacardiaceae), o juazeiro Ziziphus joazeiro (Rhamnaceae,) e o marmeleiro Croton blanchetianus (Euphorbiaceae).

\section{Obtenção dos extratos vegetais}

Foram utilizadas amostras de folhas das espécies das plantas selecionadas. Depois de colhido, o material foi submetido a banho de desinfecção em solução de cloro ativo a 0,05\% durante 20 minutos (Vieira et al., 2006). Em seguida, foi lavado em água destilada e seco em estufa $\left(45^{\circ} \mathrm{C}\right)$ por 48 horas, sendo posteriormente moído com o auxílio de almofariz e pesado. As concentrações dos extratos foram selecionadas com base no trabalho de Siqueira (2013), as quais corresponderam a $10 \%$, $15 \%, 20 \%$, obtidas obedecendo a relação peso de folha para cada $100 \mathrm{~mL}$ de água (10; 15 e $20 \mathrm{~g}$ de folha/100 $\mathrm{mL}$ de água). O material foi abrigado da luz até a obtenção do extrato bruto por um período de três dias. Todos os extratos obtidos foram guardados em vidros hermeticamente fechados e escuros e mantidos em refrigerador a $4^{\circ} \mathrm{C}$ para posterior utilização nos bioensaios. O material testemunho

Rev. Bras. PI. Med., Campinas, v.17, n.4, supl. I, p.790-797, 2015. 
de cada espécie foi identificado pelo pesquisador Dr. André Laurênio de Melo (UAST) e encontra-se armazenado no Herbário do Semiárido do Brasil (HESBRA) da UFRPE (Tabela 1).

\section{Teste de toxicidade}

Discos foliares $(3 \mathrm{~cm} \varnothing)$ de pinhão-manso foram recortados, lavados com água destilada e secos à temperatura ambiente. Em seguida, os discos foram mergulhados, por cinco segundos, em um dos extratos (aroeira, marmeleiro ou juazeiro) em diferentes concentrações $(0 \%, 5 \%, 10 \%, 15 \%$, $20 \%$ e $25 \%$ ), compreendendo, por exemplo, $25 \mathrm{~g}$ de massa verde para $100 \mathrm{~mL}$ de água destilada. Depois de impregnados com o extrato os discos foram transferidos individualmente para placas de Petri contendo substrato ágar-ágar colocando-se ao redor do mesmo algodão hidrófilo umedecido em água destilada para manter a umidade. Em cada disco foram colocadas 10 fêmeas adultas de T. bastosi, com o auxilio de pincel. As arenas foram mantidas em câmara climatizada a $25 \pm 2{ }^{\circ} \mathrm{C}, 70 \% \pm 5$ UR e $12 \mathrm{~h}$ de fotofase. Decorridas $48 \mathrm{~h}$ do confinamento dos ácaros nas arenas, efetuou-se a contagem dos indivíduos vivos e mortos, descartando-os em seguida. O delineamento estatístico adotado foi o inteiramente casualizado, com seis tratamentos (Testemunha e concentrações) e 10 repetições. Os dados foram submetidos à análise de regressão.

\section{Efeito repelente}

Para o efeito repelente a impregnação dos discos foliares seguiu a mesma metodologia utilizada no teste de toxicidade. Em seguida, os discos foram transferidos para placas, do tipo Gerbox, contendo substrato ágar-agar, de maneira a se ter em cada arena dois discos foliares por placa, sendo um tratado com um dos extratos e outro com água destilada (testemunha), interligados por uma lamínula (18x18mm). (Adaptado de Esteves-Filho, 2010). No centro da lamínula foram liberadas 10 fêmeas adultas de $T$. bastosi, as quais poderiam se movimentar entre os discos e escolher o melhor substrato para alimentação. As arenas foram mantidas em câmara climatizada do tipo B.O.D. $\left(25 \pm 2{ }^{\circ} \mathrm{C}\right.$, UR $70 \% \pm 5$ e fotofase $\left.12 \mathrm{~h}\right)$. Decorridas $48 \mathrm{~h}$ da liberação dos ácaros, efetuou-se a contagem dos indivíduos vivos e mortos em cada tratamento. $O$ delineamento estatístico adotado foi o inteiramente casualizado, com seis tratamentos (Testemunha e concentrações) e 10 repetições. Os dados foram analisados pelo Teste $\mathrm{T}$.

A porcentagem de repelência dos extratos foi calculada usando-se a fórmula adaptada de Obeng-Ofori (1995): PR = [(NC - NT) / (NC + NT) $x$ 100], sendo $P R=$ porcentagem de repelência; $N C=$ número de ácaros atraídos na testemunha e NT= número de ácaros atraídos no extrato. Para verificar a repelência dos extratos utilizados foi feito calculado o Índice de Repelência (IR) pela fórmula: IR = 2G/ $(G+P)$, onde $G=\%$ de ácaros atraídos no tratamento e $\mathrm{P}=\%$ de ácaros atraídos na testemunha. Os valores de IR variam entre zero e dois, sendo que $I R=1$ indica repelência semelhante entre o tratamento e a testemunha (tratamento neutro), IR $>1$ indica menor repelência do tratamento em relação à testemunha (tratamento atraente) e IR $<1$ corresponde à maior repelência do tratamento em relação à testemunha (tratamento repelente). O intervalo de segurança utilizado para considerar se o extrato aquoso é ou não repelente foi obtido a partir da média dos IR (índice de repelência) e do respectivo desvio padrão (DP), ou seja, se a média dos IR for menor que 1 - DP, o extrato aquoso é repelente; se a média for maior que 1 + DP o extrato aquosos é atraente e se a média estiver entre 1 - DP e 1 + DP o extrato aquoso é considerado neutro. Este índice é uma adaptação da fórmula citada por Lin et al. (1990) para índice de consumo.

\section{RESULTADOS E DISCUSSÃO}

As mortalidades ocasionadas pela aplicação dos extratos de $M$. urundeuva, C.blanchetianus e Z. joazeiro se ajustaram ao modelo polinomial quadrático $(P \leq 0,05)$ e os coeficientes de determinação $\left(R^{2}\right)$ foram superiores a 0,71 (Figura $1 a, b, c)$.

TABELA 1. Espécies de plantas da Caatinga utilizadas para obtenção dos extratos aquosos avaliados sobre Tetranychus bastosi em pinhão-manso.

\begin{tabular}{lllll}
\hline Nome Científico & Família & Nome vulgar & Voucher & Local de coleta \\
\hline Croton blanchetianus & Euphorbiaceae & Marmeleiro & S.S. Matos, $n^{\circ} 644$ & Serra Talhada - PE \\
Ziziphus joazeiro & Rhamnaceae & Juazeiro & S.S. Matos, $n^{\circ} 391$ & Serra Talhada - PE \\
Myracrodruon urundeuva & Anacardiaceae & Aroeira-do-sertão & S.S. Matos, $n^{\circ} 455$ & Serra Talhada - PE \\
\hline
\end{tabular}

Rev. Bras. PI. Med., Campinas, v.17, n.4, supl. I, p.790-797, 2015. 
Para o extrato de $M$. urundeuva houve efeito das concentrações sobre a mortalidade de $T$. bastosi $(\mathrm{F}=19,00 ; \mathrm{P}=0,025)$. A taxa de mortalidade deste ácaro variou de 0 a $70 \%$, de acordo com as concentrações, sendo observada maior mortalidade na de $25 \%$ (Figura 1a). Não houve diferença significativa na taxa de mortalidade dos ácaros nas concentrações de 5\%, 10 e 15\% do extrato. Com base nesses resultados a concentração de $25 \%$ pode ser indicada no manejo do controle de $T$. bastosi, aliada a outras estratégias de controle como o controle biológico, uma vez que já se observa mortalidade superior a $50 \%$ da população. (Figura 1a). Esses resultados corroboram com Siqueira (2013) que utilizando o extrato de $M$. urundeuva sobre Mononychelus tanajoa (Acari: Tetranychidae), nas mesmas concentrações testadas no presente estudo, observou que na concentração de $25 \%$ também ocorreu mortalidade superior a $50 \%$ da população do referido ácaro.

Para o extrato de $C$. blanchetianus a análise de regressão também demonstrou efeito significativo das concentrações sobre a mortalidade de T. bastosi $(F=21,02 ; P=0,026)$. Observou-se uma relação positiva entre a taxa de mortalidade de $T$. bastosi e o aumento das concentrações do extrato até a de $15 \%$, onde a partir daí começou a se estabilizar (Figura 1b). Na concentração de 10\% foi observada mortalidade próxima a $40 \%$ da população, a qual apresentou valores inferiores com o aumento das mesmas (Figura 1b). Estes resultados diferem dos observados por Siqueira (2013) que observou mortalidade de aproximadamente $30 \%$ nesta mesma concentração. Ainda, segundo o autor, apenas nas concentrações de 20 e $25 \%$ é que houve mortalidade acima de $50 \%$ (Figura 1b).

Com base nesses resultados a concentração de $10 \%$ é indicada para o manejo de T. bastosi, integrando outras práticas de controle, uma vez que já se observa mortalidade próxima a $50 \%$ da população (Figura 1b), fator esse de extrema importância no que se refere à economia de produto a ser empregado no controle da referida praga.

Em relação à $Z$. joazeiro foi observado efeito significativo das concentrações utilizadas sobre a mortalidade de $T$. bastosi $(F=19,28 ; P=$ 0,020 ). A taxa de mortalidade variou de 0 a $90 \%$. $\mathrm{Na}$ concentração de 5\% (menor dosagem utilizada) observou-se a maior taxa de mortalidade, próxima a $90 \%$ dos indivíduos, a qual foi bastante inferior nas concentrações seguintes (Fig. 1c). Com base nesses resultados é indicada a concentração de $5 \%$ para o controle de $T$. bastosi, uma vez que já se observa mortalidade superior a $50 \%$ da população (Fig.1c).

Potenza et al. (2006) avaliaram o efeito de extratos aquosos sobre Tetranychus urticae em casa de vegetação e verificaram que os extratos de Sonchus oleraceus (Asteraceae) e Impatiens walleriana (Balsaminaceae) provocaram respectivamente, $66,5 \%$ e $60,4 \%$ de redução da na população de Tetranychus urticae. Lucini et al. (2010) avaliaram o extrato aquoso de pimenta dedo-de-moça, Capsicum baccatum (Solanaceae), e verificaram que seu efeito não afeta a mortalidade de adultos Tetranychus ludeni em feijão comum e que houve uma redução na oviposição do ácaro com o aumento das concentrações.

De acordo com Vieira et al. (2006) os extratos aquosos e hidroalcóolicos de Mentha piperita (Lamiaceae), Mentha spicata (Lamiaceae) e Mentha suaveolens (Lamiaceae) proporcionaram mortalidade acima de $90 \%$ de fêmeas de Tetranychus urticae após 120 horas de exposição. O fato do período de exposição aos extratos utilizados no presente estudo ter sido apenas de $48 \mathrm{~h}$, pode ter influenciado na taxa de mortalidade, assim com o tipo de solvente utilizado na obtenção dos extratos, o que pode explicar as baixas taxas de mortalidade para determinadas concentrações utilizadas. Logo, é importante avaliar o efeito de diferentes períodos de exposição de $T$. bastosi aos extratos aqui avaliados, de maneira a se assegurar se isso irá contribuir para a obtenção de maiores taxas de mortalidade deste ácaro ou se realmente, em algumas das concentrações utilizadas, a atividade acaricida é baixa.

A mortalidade ocasionada pelo extrato de M. urundeuva sobre $T$. bastosi pode ser decorrente da presença de taninos, que são os principais componentes encontrados nessas plantas (Queiroz et al., 2002). Essas substâncias são classificadas como substâncias quantitativas, por serem redutores digestivos, com efeito proporcional à concentração (Strong et al., 1984). Reduzem, significativamente, o crescimento e a sobrevivência de artrópodes, uma vez que inativam enzimas digestivas e criam um complexo de taninos-proteínas de difícil digestão (Mello \& Silva-Filho, 2002).

Já no que se refere a $C$. blanchetianus estudos têm demonstrado efeito acaricida de seus extratos (Pontes, 2007; Siqueira, 2013), o qual tem sido relacionado à presença de compostos secundários presentes nas folhas, cujos componentes majoritários, segundo Angélico (2011), são o cedrol, eucaliptol e o a-pipeno.

Em relação a Z. joazeiro, as saponinas e a cafeína têm sido relatadas como um dos principais compostos secundários presentes nas folhas desta espécie (Lima, 2008). Além disso, outros compostos como o ácido omealóico, butolínico, amido, vitamina C, sais minerais e proteínas foram isolados por Lima (1989). A presença de cafeína exerceu efeito inibitório no crescimento de fungos (Chalfoun, 2000; Brand, 2002). Já em relação às saponinas,

Rev. Bras. PI. Med., Campinas, v.17, n.4, supl. I, p.790-797, 2015. 

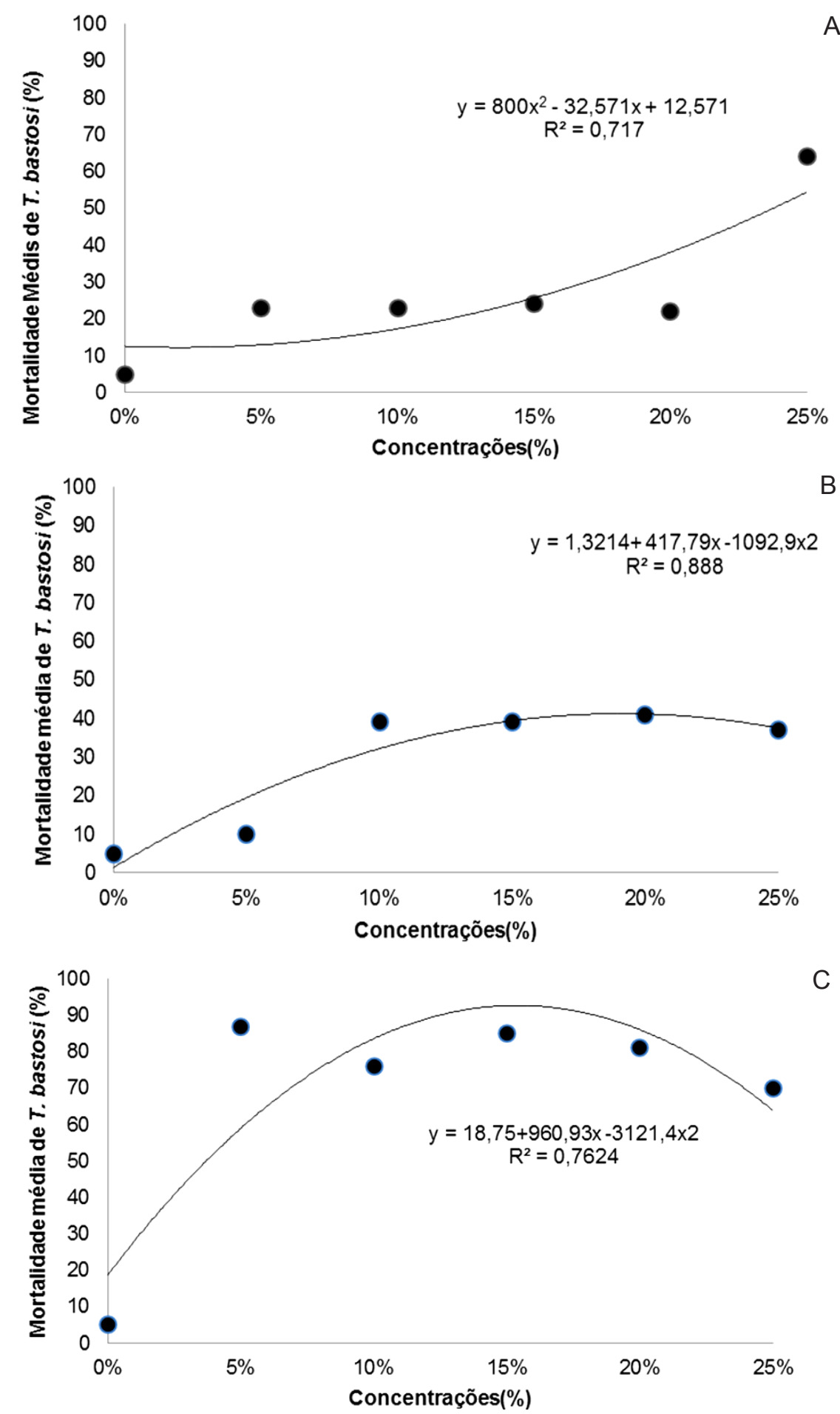

FIGURA 1. Mortalidade média de Tetranychus bastosi em função das concentrações dos extratos aquosos de (a) Myracrodruon undureuva; (b) Croton blanchetianus; (c) Ziziphus joazeiro (c) após o período de 48 h (25 \pm 1 ${ }^{\circ} \mathrm{C} ; 70 \%$ UR e fotofase de $12 \mathrm{~h}$ ).

segundo Taiz \& Zeiger, (1991), sua toxicidade devese á capacidade de formar complexos esteroides, dificultado sua absorção ou desorganizando membranas celulares. E ainda é relatada a presença de ácido betulínico, ácido oleanólico e saponina (Barbosa-Filho et al., 1985; Higuchi et al., 1984). A
A

B

C 
(Euphorbiaceae), Azadiractina A/B e Azadiractina $1 \%$ foram repelentes para $T$. urticae, a partir da primeira hora de avaliação até o final do experimento (após $48 \mathrm{~h}$ de exposição). Observaram ainda que Azadiractina A/B e Azadiractina 1\% causaram 100\% de repelência e $J$. curcas $96,9 \%$.

De acordo com Oliveira et al. (2010) os extratos de folha de $M$. urundeuva (Anarcadiaceae) apresentaram alto teor de fenólicos totais quando comparados com a $S$. terebinthifolius (Anarcadiaceae). Ainda de acordo com os autores o extrato de casca desta espécie apresentou melhor atividade antifúngica, tendo maior inibição com 50\% de crescimento.

A atividade acaricida de extratos de plantas e de outras substâncias de origem natural vem se configurando em um caminho promissor para o controle de pragas. Novos estudos devem ser feitos para avaliar a relação custo/ benefícios da utilização destes produtos em grande escala para a proteção de espécies comerciais. Estes dados representam o primeiro relato da atividade acaricida do extrato de aroeira sobre $T$. bastosi. Informações de grande relevância para a produção do pinhãomanso na região do semiárido, uma vez que poderá proporcionar aos produtores rurais o uso de tática alternativa aos inseticidas químicos tradicionais para o controle de praga na referida cultura, favorecendo assim a redução dos custos envolvidos na utilização deste método de controle.

De uma forma geral, todos os tratamentos se mostraram repelentes para fêmeas de T. bastosi, classificados como tratamentos repelentes, exceto para a dosagem de $5 \%$ do extrato de aroeira, a qual obteve um índice de repelência igual a 1,00, sendo, portanto, classificado como tratamento neutro (Tabela 2).

O efeito repelente intrínseco de algumas plantas tem sido apontado como uma forma eficaz em evitar a infestação de pragas em diversas culturas agrícolas, levando consequentemente à redução da permanência da praga em campo, reduzindo a oviposição e que completem seu ciclo de desenvolvimento, e consequentemente, as perdas na produtividade, trazendo benefícios econômicos (Andrade et al., 2013).

Dessa forma, os dados revelaram que o uso do extrato de $Z$. joazeiro demonstrou potencial de controle sobre a mortalidade de $T$. bastosi, uma vez que provocou em uma dosagem baixa do extrato, mortalidade de $90 \%$ (Tabela 2). Embora essa dosagem tenha apresentado efeito neutro, quando avaliado o seu índice de repelência, isso não afeta seu potencial, pois mesmo que a praga permaneça na planta e não seja repelida pelo produto, ela vai ser afetada pela toxicidade, conforme o teste de toxicidade demonstrou. Os demais tipos de extrato C. blanchetianus e M. unrundeuva

TABELA 2. Índice de repelência $( \pm D P)$ de extratos vegetais aquosos, em diferentes concentrações, sobre $T$. bastosi em pinhão-manso no período de $48 \mathrm{~h}$ ( $25 \pm 1^{\circ} \mathrm{C} ; 70 \%$ UR e fotofase de $12 \mathrm{~h}$ ).

\begin{tabular}{|c|c|c|c|c|}
\hline EXTRATO & CONCENTRAÇÃO & $\mathrm{IR} \pm \mathrm{DP}^{1}$ & $\mathrm{C}^{2}$ & $\mathrm{IS}^{3}$ \\
\hline \multirow{5}{*}{ Myracrodruon urundeuva } & $25 \%$ & $0,9 \pm 3,20$ & $\mathrm{R}$ & $\mathrm{R}$ \\
\hline & $20 \%$ & $0,4 \pm 3,34$ & $\mathrm{R}$ & $\mathrm{R}$ \\
\hline & $15 \%$ & $0,26 \pm 3,68$ & $\mathrm{R}$ & $\mathrm{R}$ \\
\hline & $10 \%$ & $0,74 \pm 2,44$ & $\mathrm{R}$ & $\mathrm{R}$ \\
\hline & $5 \%$ & $0,54 \pm 2,91$ & $\mathrm{R}$ & $\mathrm{R}$ \\
\hline \multirow{5}{*}{ Croton blanchetianus } & $25 \%$ & $0,3 \pm 3,71$ & $\mathrm{R}$ & $\mathrm{R}$ \\
\hline & $20 \%$ & $0,5 \pm 2,95$ & $\mathrm{R}$ & $\mathrm{R}$ \\
\hline & $15 \%$ & $0,7 \pm 1,74$ & $\mathrm{R}$ & $\mathrm{R}$ \\
\hline & $10 \%$ & $0,78 \pm 1,80$ & $\mathrm{R}$ & $\mathrm{R}$ \\
\hline & $5 \%$ & $0,7 \pm 2,49$ & $\mathrm{R}$ & $\mathrm{R}$ \\
\hline \multirow{5}{*}{ Ziziphus joazeiro } & $25 \%$ & $0,76 \pm 1,65$ & $\mathrm{R}$ & $\mathrm{R}$ \\
\hline & $20 \%$ & $0,5 \pm 3,35$ & $\mathrm{R}$ & $\mathrm{R}$ \\
\hline & $15 \%$ & $0,74 \pm 2,02$ & $\mathrm{R}$ & $\mathrm{R}$ \\
\hline & $10 \%$ & $0,48 \pm 3,11$ & $\mathrm{R}$ & $\mathrm{R}$ \\
\hline & $5 \%$ & $1,0 \pm 1,37$ & $\mathrm{~N}$ & $\mathrm{~N}$ \\
\hline
\end{tabular}

1 Índice de Repelência ; DP = desvio Padrão; C= Classificação ; IS = Intervalo de segurança; $\mathrm{R}$ = repelente; $\mathrm{N}=$ neutro. 
demonstram mortalidade médias inferiores a 50\% da população para as diferentes dosagens (Tabela 2), sendo mais indicado nesse caso sua utilização associado a outros métodos de controle, como o controle biológico, desde que sejam feitos testes de seletividade do extrato para os inimigos naturais, os ácaros predadores fitoseídeos.

No que se refere ao efeito repelente, considerando o índice de segurança e seus respectivos desvios padrão, verificou-se que todos demonstraram efeito repelente à $T$. bastosi. $O$ efeito repelente é uma característica bastante importante para qualquer produto que se destina para o controle de praga, uma vez que afeta diretamente a praga.

Dessa forma, dependendo da necessidade do produtor, todos os extratos podem ser recomendados. C. blanchetianus e $M$. unrundeuva podem ser utilizados juntos com outros métodos de controle, por serem repelentes à praga. E Z. joazeiro, embora tenha sido classificado como neutro na dosagem de $5 \%$, pode ser utilizado no controle de T. bastosi, uma vez que apresentou alta taxa de mortalidade.

Os extratos de M. urundeuva e Z. joazeiro demonstraram potencial para o manejo de T. bastosi, aliado a outras estratégias de manejo integrado de pragas, uma vez que foram encontrados valores superiores a $50 \%$ de mortalidade dos indivíduos e apresentaram-se repelentes à praga. Porém testes de seletividade utilizando os referidos extratos devem ser feitos com ácaros predadores, principalmente da família Phytoseiidae, uma vez que estes ácaros são os principais inimigos naturais associados à $T$. bastosi no pinhão-manso.

\section{AGRADECIMENTOS}

À Unidade Acadêmica de Garanhuns e ao Programa de Pós-Graduação em Produção Agrícola. À Unidade Acadêmica de Serra Talhada pela concessão do espaço de laboratórios para realização deste trabalho e à Fundação de Amparo à Ciência e Tecnologia pela concessão de bolsa de estudos.

\section{REFERÊNCIAS}

ANDRADE, L.H. et al. Efeito repelente de azadiractina e óleos essenciais sobre Aphis gossypii Glover (Hemiptera: Aphididae) em algodoeiro. Revista Ciência Agronômica, v.44, n.3, p. 628-634, 2013.

ALVES, J.M.A. et al. Pinhão-manso: uma alternativa para produção de biodiesel na agricultura familiar da Amazônia brasileira. Agroambiente. Boa Vista, v.2, n.1, p.57-68, 2008.

ANGÉLICO, E.C. Avaliação das atividades antibacterianas e antioxidantes de Croton heliotopiifolius Kunte e Croton blanchetianus
Baill. 2011. 86 p. Dissertação (Mestrado), Universidade Federal de Campina Grande, Patos, Paraíba.

ARRUDA, F.P.; BELTRÃO, N.E.M.; ANDRADE, A.P.; PEREIRA, W.E.; SEVERINO, L.S. Cultivo de pinhãomanso (Jatropha curca L.) como alternativa para o semiárido nordestino. Revista Brasileira de Oleaginosas e Fibrosas, v.8, n.1, p.789-799, 2004.

BARBOSA FILHO, J.M.; TRIGUEIRO J.A.; CHERIYAN U.O, B.J. Constituents of the Stem-Bark of Zizyphus joazeiro. Journal of Natural Products, v.48 n.1, p.1523, 1985.

BARROS, A.M.F. Aspectos bioecológicos e populacionais de Tetranychus bastosi (ACARI: TETRANYCHIDAE) em pinhão-manso no semiárido pernambucano. 2013. 46 p. Dissertação (Mestrado em Produção Agrícola). Universidade Federal Rural de Pernambuco. Garanhuns.

BRAND. D. Relationship between coffe husk caffeine degration and respiration of Aspergillus sp LPBx in solid-state fermentation. Applied Biochemistry and Biotechnologyn.102, p.169-177, 2002.

CHALFOUN, S. M. Efeito da cafeina (1,3,7triemethylxanthina) sobre o crescimento micelial de fungos associados ao café. Revista Brasileira de Armazenamento Especial. n.1, p.50-53, 2000.

ESTEVES FILHO, A.B. Toxicidade, efeito residual e repelência de acaricidas sintéticos e produtos naturais sobre Tetranychus urticae koch e Phytoseiulus macropilis (BANKS), em algodoeiro. 2010. 83p. Tese (Doutorado em Entomologia Agrícola)Universidade Federal Rural de Pernambuco, Recife.

HIGUCHI, R.; KUBOTA, S.; KOMORI, T.; KAWASAKI, T.; PANDEY, V.B.; SINGH, J.P.; SHAH, A.H. Triterpenoid saponins from the bark of Zizyphus joazeiro. Phytochemistry Journal. v. 23. n. 11. p. 2597-2600, 1984.

HELLER, J. P.N.. Jatropha curcas L.: promoting the conservation and use of underutilized and neglected crops. International Plant Genetic Resources Institute. 1 ed. Italy, Institute plant genetic resourcer institute, 1996, 66 p.

LARCHER, W. Ecofisiologia vegetal. Rima. São Carlos, 2000. 519 p.

LIMA, D.A.; Plantas da Caatinga. Rio de Janeiro. A tribuna dos Santos. 1989. 243 p.

LIMA, P.M. Avaliação da atividade de extratos de folhas de Momordica charantia, Auxemma oncocalyx e Ziziphus joazeiro sobre bactérias e larvas de Culex quinquefasciatus. 2008. 67 p. Dissertação (Mestrado em Ciência Animal). Universidade Federal Rural do Semi-Árido, Mossoró.

LIMA, R. L. S.; SEVERINO, L. S.; CAZETTA, J. O.; AZEVEDO, C. A. V.; SOFIATTI, V.; ARRIEL, N. H. C. Redistribuição de nutrientes em folhas de pinhãomanso entre estádios fenológicos. Revista Brasileira de Engenharia Agrícola e Ambiental, v. 15, p. 11751179, 2011.

$\mathrm{LIN}, \mathrm{H}$; et al., Induced resistance in soybean to the Mexican bean beetle (Coleoptera: Coccinellidae): comparisons of inducing factors. Environmental Entomology v. 19: p.1852-1857, 1990.

LUCINI, T.; SCABENI, C.; DEDORDI, E.; HIROSE, C.; SHIOMI, H. F.. Efeito de extrato aquoso de Capsicum

Rev. Bras. PI. Med., Campinas, v.17, n.4, supl. I, p.790-797, 2015. 
baccatum na mortalidade e oviposição de Tetranychus Iudeni (ACARI: TETRANYCHIDAE). Scientia Agraria, v. 11, n. 4, p. 355-358, 2010.

MATOS, C.H.C. Mecanismos de defesa constitutiva em espécies de pimenta Capsicum e sua importância no manejo do ácaro branco Polyphagotarsonemus latus (Banks, 1904) (Acari: Tarsonemidae). 2006. 59 p. Tese (Doutorado em Entomologia). Universidade Federal de Viçosa, Viçosa.

MELLO, M. O.; SILVA-FILHO, M. C. Plant-insect interactions: an evolutionary arms race between two distinct defense mechanism. Brazilian Joural of Plant Physiology, v. 14, p. 71-81, 2002.

OBENG-OFORI, D. Plant oils as grain protectants against infestations of Cryptolestes pussilus and Rhyzopertha dominica in stored grain. Entomologia Experimentalis et Applicata, v.77, p.133-139, 1995.

OLIVEIRA, A.F.M.; SALATINO, A. Major constituents of the epicuticular waxes of species from the caatinga and cerrado. Zeitschrift für Naturforschung, v.55, p.688-92, 2000.

OLIVEIRA, C.S.C.; GOMES JUNIOR, R.A.; RIBEIRO, P.R.; ALMEIDA, M. C.; VANNIER, M.A.S.; DE CASTRO, R.D.; FERNANDEZ, L.G. Avaliação da atividade antifúngica de extratos de Myracrodruon urundeuva Fr. All Allemao e Schinus terebinthifolius Raddi em Candida albicans e C. tropicalis. Agroindústria, qualidade de vida e biomas brasileiros. Disponível em: http://www. abq.org.br/cbq/2010/trabalhos/7/7-261-8190.htm . Acesso em: 16 jun.2014.

PEDRO NETO, M.; SARMENTO, R. A.; OLIVEIRA, W, P.; PICANÇO, M. C.; ERASMO, E. A. L. Biologia e tabela de vida do ácaro-vermelho Tetranychus bastosi em pinhão-manso. Pesquisa agropecuária brasileira. v.48, n.4, p.353-357, 2013.

PONTES, W.J.T.; OLIVEIRA, J.C.G.; CÂMARA, C.A.G.; LOPES A.C.H.R.; GONDIM JÚNIOR, M.G.C.; OLIVEIRA, J.V.; BARROS,R.; SCHWARTZ, M.O.E. Chemical composition and acaricidal activity of the leaf and fruit essential oils of Protium heptaphyllum (Aubl.) Marchand (Burseraceae). Acta Amazônica. v. 37 p. $103-110,2007$.

POTENZAM.R.; GOMES, R.C.O.; JOCYS,T.; TAKEMATSU, A.P.; RAMOS A.C.O. Avaliação de produtos naturais para o controle do ácaro rajado Tetranychus urticae (KOCH, 1836) (ACARI: TETRANYCHIDAE) em casa de vegetação. Arquivos do instituto Biológicov.73, n.4, p.455-459, 2006.

QUEIROZ, C.R.A.A.; MORAIS, S.A.L.; NASCIMENTO, E.A. Caracterização dos taninos da aroeira-preta (Myracrodruon urundeuva). Revista Árvore, v.26, p.485-492, 2002.

SIQUEIRA, F. F. S. Potencial de Extratos Aquosos de Plantas da Caatinga sobre o Ácaro Verde da Mandioca Mononichellus tanajoa BONDAR (ACARI: TETRANYCHIDAE). 2013. 35 p.. Dissertação. (Mestrado em Produção Vegetal). Universidade Federal Rural de Pernambuco. Serra Talhada.

SOTO, A., VENZON, M.; PALLINI, A. Integración de control biológico y de productos alternativos contra Tetranychus urticae (ACARI: TETRANYCHIDAE). Actualidad y Divulgación Científica, v.14 n.1), p. 23-29. 2011.

STRONG, D.R.; LAWTON, J.H.; SOUTHWOOD, T.R.E. Insects on plants: community patterns and mechanisms. London. Blackwell Scientific, 1984. 313p.

TAIZ L.; ZEIGER E. Surface protection and secondary metabolites defense compounds. In: TAIZ, L.; ZEIGER, E. (Ed.). Plant Physiology. Califórnia: Cummins Company, 1991, 318-345..

VANZOLINE, S.; MEORIN, E.B.K.; NAKAGAWA, R.A.D.S.E.J. Qualidade sanitária e germinação de sementes de pinhão-manso. Revista Brasileira de Sementes, v. 32, p. 009-014, 2010.

VERONA, R. L. C. Ácaros Associados à Jatropha spp. (Euphorbiaceae) no Brasil. 2010, 71 p. Dissertação (Mestrado em Biologia Animal), Universidade Estadual Paulista, São José do Rio Preto.

VIEIRA, M.R.; SACRAMENTO, L.V.S.; FURLAN. L.O.; FIGUEIRA.J.C.; ROCHA.A.B.O. Efeito Acaricida de Extratos Vegetais sobre fêmeas de Tetranychus urticae Koch (ACARI: TETRANYCHIDAE) Revista Brasileira de Plantas Medicinais. v.8. n. 4; p. 210-217, 2006.

VISSER, E.M.; OLIVEIRA FILHO, D.; MARTINS, M.A.; STEWARD, B.L. Bioethanol production potential from Brazilian biodiesel co-products. Biomass and bioenergy, v. 35, p. 489-494, 2011.

WANG, R.; SONG, B.; ZHOU, W.; ZHANG, Y.; HU, D.; BHADURY, P. S.; YANG, S. A facile and feasible method to evaluate and control the quality of Jatropha curcas L. seed oil for biodiesel feedstock: Gas chromatographic fingerprint. Applied Energy, v. 88, p. $2064-2070,2011$.

Rev. Bras. PI. Med., Campinas, v.17, n.4, supl. I, p.790-797, 2015. 